\title{
PERFORMANCE INVESTIGATION OF OPTICAL TRANSMISSION SYSTEM USING DCF-EDFA TECHNIQUES
}

\author{
M.L. Meena and Pragya Purohit \\ Department of Electronics Engineering, Rajasthan Technical University, India
}

\begin{abstract}
In this paper, a single channel optical system is proposed with dispersion compensation fiber techniques. Dispersion compensation method restricts the pulse broadening consequence of transmitted pulse in optical systems. To overcome dispersion trouble; dispersion compensation scheme modeled for investigate the performance of optical system. The proposed model is designed for 10Gbps with nonreturn-to-zero (NRZ) modulation format with erbium doped fiber amplifier (EDFA) over a length of $15 \mathrm{~km}$ single mode fiber (SMF) and $3 \mathrm{~km}$ dispersion compensation fiber (DCF). The performance of designed model is analyzed in terms of output power (dBm), gain (dB), noise figure (dB), $Q$-factor, BER and Eye-diagrams by varying the fiber length (km), input power ( $\mathrm{dBm})$ and attenuation constant $(\mathrm{dB} / \mathrm{km})$. The simulation is carried out in Opti-System 7.0 simulator.
\end{abstract}

Keywords:

Bit Error Rate, Dispersion Compensation Fiber, Erbium Doped Fiber Amplifier, Non-Return-to-Zero

\section{INTRODUCTION}

Recently, the demand of optical fiber technology is increased day by day in telecommunication industry due to large bandwidth, high data rate and low cost reliable optical communication links. The transmission in optical network is mainly effected, when different wavelength signals are transmitted over an optical fiber, these optical signals travel with different speeds due to the variations in core and cladding refractive index. Therefore, the optical signals are overlap/broaden/spread out after travel a long distance through fiber. Hence the broadening of pulse causes dispersion and losses in transmitted signals which lead to error signal at receiver end [1]-[3]. Therefore, attenuation loss and dispersion are the major factor that affect optical network. In order to overcome the attenuation problem, erbium doped fiber amplifier (EDFA) is introduced as shown in Fig.1. To amplify the optical signal, EDFA is the most frequently used optical amplifier (OA) because it works on low loss $1550 \mathrm{~nm}$ wavelength window of silica based fiber [4]-[6].

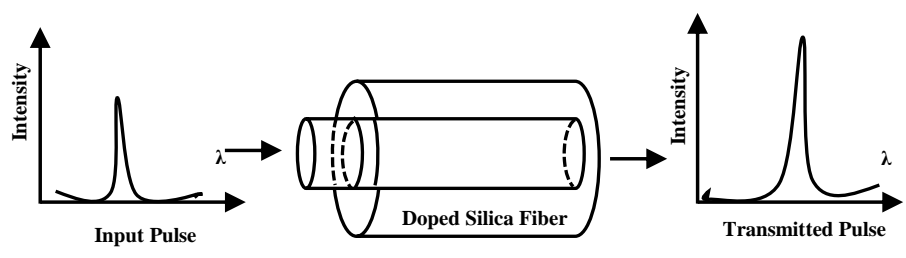

Fig.1. Basic principal of EDFA amplifier

In optical transmission system, dispersion is the key issue to restrict the long distance optical fiber communication [7], [8]. To overcome dispersion issue, the most efficient technique that is Dispersion Compensation Fiber (DCF) is introduced having negative dispersion coefficient to compensate the effect of positive dispersion in an optical fiber communication link [9]. However, DCF technique increases insignificant nonlinear effects but it is low cost, simplicity, highly reliable and easy to upgrade of already installed links of single mode fiber (SMF) in an optical network [10]-[16].

In this paper, we investigate the performance of $10 \mathrm{Gbps}$ optical transmission system using dispersion compensation fiber technique. The optimized parameters of SMF and DCF are identified and after simulation, performance parameters of the proposed model are analyzed for single channel in terms of output power $(\mathrm{dBm})$, gain $(\mathrm{dB})$, noise figure $(\mathrm{dB}), \mathrm{Q}$-factor, BER and Eye-diagram for NRZ modulation scheme. Main aim of presented work is to improve the performance of proposed model by reducing dispersion and attenuation phenomena through DCF techniques and EDFA amplifier, respectively. The designed optical configurations are modeled and simulated using advanced tools of Opti-System7.0 simulator.

\section{DISPERSION TECHNIQUES}

COMPENSATION

Dispersion supervision plays an important role for designing of optical transmission systems because; dispersion degrades the performance of longer optical transmission link due to the fiber nonlinearity. So, dispersion compensation fiber (DCF) is the most universal technique to reduce the impact of dispersion. For this purpose, a special single mode fiber is designed to reverse the deleterious consequence of dispersion and improve the transmission quality of optical fiber. Therefore, the DCF has a higher negative dispersion coefficient around $-80 \mathrm{ps} / \mathrm{nm}-\mathrm{km}$ fibers can be linked to the SMF having positive dispersion coefficient of $16 \mathrm{ps} / \mathrm{nm}-\mathrm{km}$ to compensate the dispersion effect as shown in Fig.2.

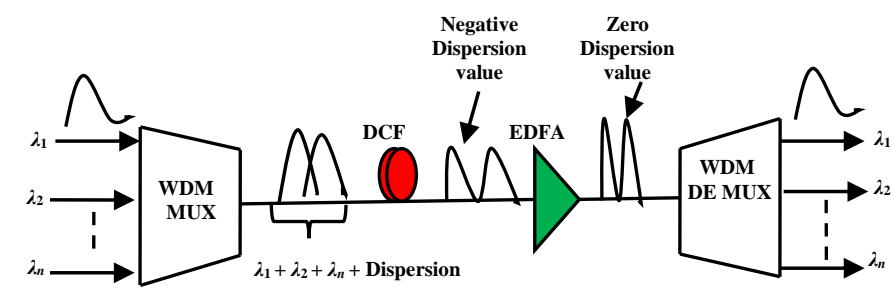

Fig.2. Basic principal of DCF Technique with EDFA optical transmission system

Hence, dispersion compensation fiber is competent to compensating the group velocity dispersion (GVD) and insignificant nonlinear effect inside the fiber if optical power is kept small. The pulse propagation equation for optical signal 
propagates through the segments of SMF and DCF at $L$ transmission distance can be given as [9]:

$$
V(L, t)=\frac{1}{2 \pi} \int_{-\infty}^{\infty} \tilde{V}(0, \omega) \exp \left(\frac{i}{2} \beta \omega^{2} L-i \omega t\right) d \omega
$$

where $\tilde{V}(0, \omega)$ is Fourier transform of pulse amplitude $V(0, t)$ and $\beta$ is GVD parameter, which is related to dispersion. Dispersion induced deficiency of optical signal is cause by the phase aspect, $\exp \left(\frac{i}{2} \beta \omega^{2} L\right)$, which can be acquired by signal during its transmit throughout the optical fiber. If the length of two fiber segments LSMF, LDCF are due to SMF and DCF, respectively then from the Eq,(1):

$$
V(L, t)=\frac{1}{2 \pi} \int_{-\infty}^{\infty} \tilde{V}(0, \omega) \exp \left(\frac{i}{2} \omega^{2}\left(\begin{array}{l}
\beta_{S M F} L_{S M F} \\
+\beta_{D C F} L_{D C F}
\end{array}\right)-i \omega t\right) d \omega
$$

where, overall length of fiber segments is $\mathrm{L}=\mathrm{L} \_\mathrm{SMF}+\mathrm{L} \_\mathrm{DCF}$ and $\beta$ SMF, $\beta$ DCF are GVD parameters for the segments of fiber length $\mathrm{LSM}$ M and LDCF, respectively. If we choose DCF then $\omega^{2}$ term disappear thus original pulse shape can be recover. Therefore, perfect condition for dispersion compensation beside DCF can be given as:

$$
\beta_{S M F} L_{S M F}+\beta_{D C F} L_{D C F}=0
$$

or

$$
D_{S M F} L_{S M F}+D_{D C F} L_{D C F}=0
$$

and

$$
D=-\frac{2 \pi c}{\lambda^{2}} \beta
$$

where, $\lambda$ is wavelength of pulse signal, $C$ is the light speed. Because in case of $S M F, D_{S M F}>0$, Eq.(4) shows that dispersion coefficient $D_{D C F}$ (in ps/nm.km) (at certain wavelength $\lambda$ in $\mathrm{nm}$ ) of DCF should be negative for dispersion compensation and length $L_{D C F}$ (in $\mathrm{km}$ ) of DCF must be satisfy as,

$$
L_{D C F}=-L_{S M F}\left(\frac{D_{S M F}}{D_{D C F}}\right)
$$

Further, to overcome remaining dispersion in very high speed optical transmission systems, the dispersion slop $S_{D C F}$ of DCF must be satisfy as,

$$
S_{D C F}=-S_{S M F} \frac{L_{S M F}}{L_{D C F}}=S_{S M F} \frac{D_{D C F}}{D_{S M F}}
$$

where, SSMF is dispersion slope of SMF. According to above analysis, the components/mechanisms of DCF are wide bandwidth performance, more stable and negligible temperature effect. Hence, DCF is the most appropriate technique for dispersion compensation. Therefore, the physical arrangement of SMF, DCF and EDFA can be situated at different positions in optical transmission system for dispersion as well as attenuation compensation. In section 3 and section 4, we discussed the proposed optical transmission model and evaluate its performance in terms of output power $(\mathrm{dBm})$, gain $(\mathrm{dB})$, noise figure $(\mathrm{dB}), \mathrm{Q}$ factor, BER and Eye-diagrams at different fiber length, input power and attenuation constant.

\section{PROPOSED SIMULATION MODEL}

A single channel optical communication system is designed for $10 \mathrm{Gbps}$ per channel transmission speed based on DCF-EDFA compensation techniques. The proposed model is simulated by software Optisystem7.0 using NRZ modulation format to investigate how dispersion altered the performance of optical transmission system. The basic principal of single channel optical transmission system model is shown in Fig.3. A single channel transmitter is constructed by data source, to produce a pseudo random sequence, NRZ pulse generator, to convert binary data into electrical pulse, continuous wave laser (CW) and MachZehnder (MZ) modulator to modulate the $\mathrm{CW}$ laser signal. The central frequency of channel is choosing on $193.1 \mathrm{THz}$ according to recommendation of ITU-TG.694.1.

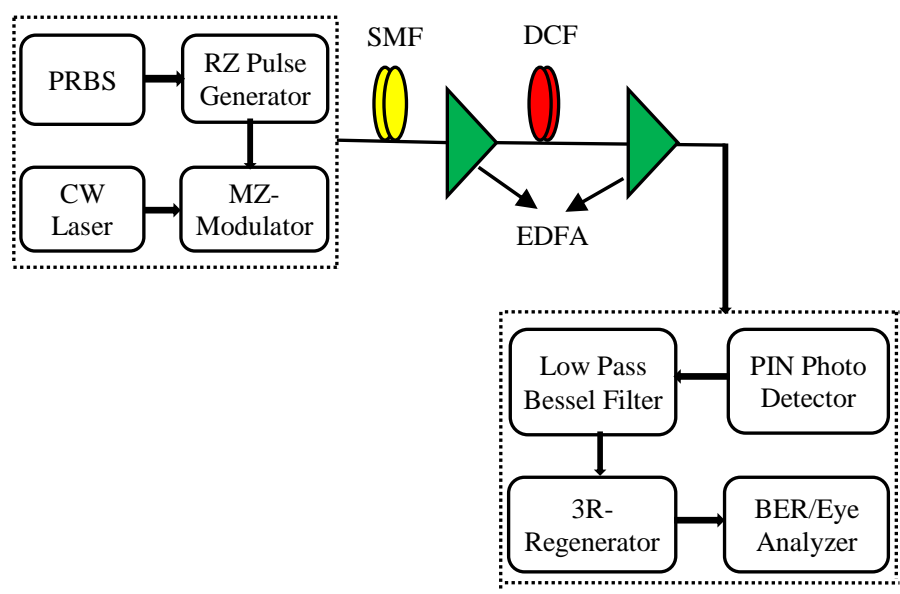

Fig.3. Principal of proposed optical transmission system using DCF-EDFA compensation techniques

The CW laser source is used for generating wavelength optical signal. The optical input signal is combine/spread over a single optical fiber consisting of SMF and DCF. The length of SMF and DCF are $15 \mathrm{~km}, 3 \mathrm{~km}$, respectively. Therefore, total transmission length of channel is $18 \mathrm{~km}$. Further, relative arrangement of DCF, SMF and Erbium doped fiber amplifier (EDFA) are preferred according to dispersion compensation techniques. EDFA is introduced to amplify the transmitted signal as shown in Fig.3. The received optical signal is given to PIN photo-detector and pass through low pass electrical Bessel filter and BER/Eye analyzer. The whole simulation model of $10 \mathrm{Gbps}$ optical transmission system is shown in Fig.4 and parameters of simulation model components are given in Table.1.

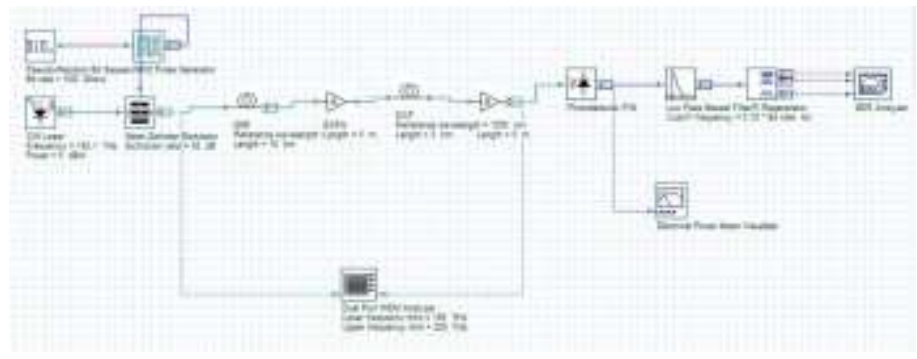

Fig.4. Proposed simulation model of 10Gbps optical transmission system using DCF-EDFA techniques 
Table.1. Basic components with parameter values of simulation model

\begin{tabular}{|c|c|}
\hline Components & Parameters \\
\hline Data source & Data rate: $10 \mathrm{Gbps}$ \\
\hline Line coder & NRZ \\
\hline CW Laser & $\begin{array}{l}\text { Output power: } 5 \mathrm{dBm} \\
\text { FWHM line width: } 10 \mathrm{MHz} \\
\text { Channel central frequency: } \\
193.1 \mathrm{THz}\end{array}$ \\
\hline $\begin{array}{l}\text { Mach-Zehnder (MZ) } \\
\text { Modulator }\end{array}$ & Extinction ratio: $30 \mathrm{~dB}$ \\
\hline $\mathrm{DCF}$ & $\begin{array}{l}\text { Length: } 3 \mathrm{~km} \\
\text { Attenuation Loss: } 0.2 \mathrm{~dB} / \mathrm{km} \\
\text { Dispersion: }-80 \mathrm{ps} / \mathrm{nm} \cdot \mathrm{km} \\
\text { Dispersion slop: }-0.37 \mathrm{ps} / \mathrm{nm}^{2} / \mathrm{km} \\
\text { Core effective area: } 25 \mu \mathrm{m}^{2}\end{array}$ \\
\hline SMF & $\begin{array}{l}\text { Length: } 15 \mathrm{~km} \\
\text { Attenuation Loss: } 0.2 \mathrm{~dB} / \mathrm{km} \\
\text { Dispersion: } 16 \mathrm{ps} / \mathrm{nm} . \mathrm{km} \\
\text { Dispersion slop: } 0.08 \mathrm{ps} / \mathrm{nm}^{2} / \mathrm{km} \\
\text { Core effective area: } 85 \mu \mathrm{m}^{2}\end{array}$ \\
\hline EDFA Gain & Variable Gain (10-30dB) \\
\hline Receiver & $\begin{array}{l}\text { Photo-detector: PIN Diode } \\
\text { Sensitivity: }-100 \mathrm{dBm} \\
\text { Error probability: } 10^{-9} \\
\end{array}$ \\
\hline Low Pass Bessel Filter & $-3 \mathrm{~dB}$ Bandwidth: $10 \mathrm{GHz}$ \\
\hline
\end{tabular}

\section{RESULTS AND DISCUSSIONS}

The performance of proposed optical transmission model is simulated on Optisystem7.0 simulator and with satisfactory standards of quality factor (Q-factor), bit error rate (BER) are measured by BER analyzer. Hypothetically, $\mathrm{Q}>6$ and $\mathrm{BER} \leq 10^{-9}$ are the acceptable values for enhanced optical communication system. Therefore, higher value of Q-factor and lower value of BER authenticate the low noisy and better optical transmission system. Performance of optical transmission system is investigate by varying the length of optical fiber (SMF), input power and attenuation coefficient parameters in comprehensive to pact with optimized subsequent parameters value as given in Table1. Initially, the performance of proposed model is investigated by varying the length of SMF with DCF-EDFA techniques. Different Eye-diagrams are evaluated from simulated model with different values of SMF length as shown in Fig.5. It can be observed that, when the length of SMF increases, closing of eye remains nearly same with slightly distorted while we compare the Eye-diagrams. The output readings of optimized performance parameters with corresponding fiber length are given in Table.2 in terms of QFactor, gain, min BER, noise figure, and output power.

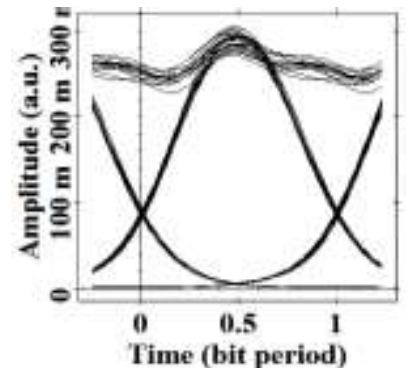

$5 \mathrm{~km}$

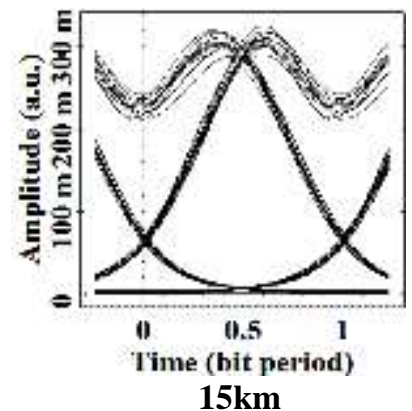

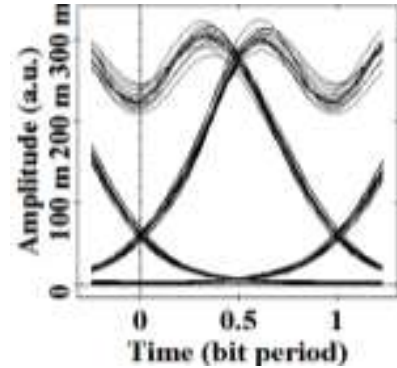

$10 \mathrm{~km}$

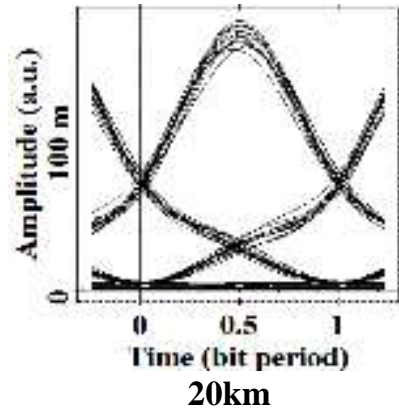

$20 \mathrm{~km}$

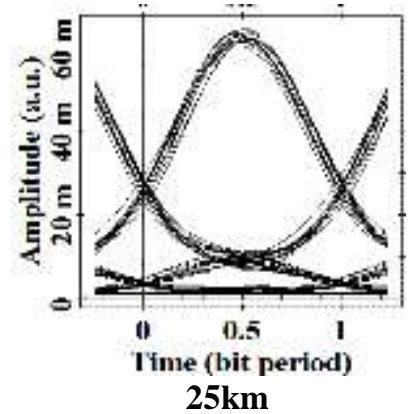

Fig.5. Eye-diagrams of received signals from proposed optical fiber transmission system with different values of SMF length

Table.2. Performance parameters of simulated model by varying SMF length

\begin{tabular}{|c|c|c|c|c|c|}
\hline $\begin{array}{c}\text { Length } \\
(\mathbf{k m})\end{array}$ & $\begin{array}{c}\text { Max Q- } \\
\text { factor }\end{array}$ & Min BER & $\begin{array}{c}\text { Gain } \\
(\mathbf{d B})\end{array}$ & $\begin{array}{c}\text { Noise } \\
\text { Figure } \\
(\mathbf{d B})\end{array}$ & $\begin{array}{c}\text { Output } \\
\text { Power } \\
(\mathbf{d B m})\end{array}$ \\
\hline 5 & 160.1183 & $1.09166 \mathrm{e}^{-174}$ & 18.975819 & 4.37252 & 16.432 \\
\hline 10 & 140.4693 & $1.14862 \mathrm{e}^{-133}$ & 18.567038 & 5.29250 & 16.079 \\
\hline 15 & 145.5749 & $1.47701 \mathrm{e}^{-119}$ & 18.499858 & 6.40983 & 16.223 \\
\hline 20 & 130.8367 & $2.18905 \mathrm{e}^{-019}$ & 17.818290 & 7.88650 & 15.697 \\
\hline 25 & 110.7412 & $2.63383 \mathrm{e}^{-037}$ & 16.284000 & 8.12069 & 15.450 \\
\hline 30 & 100.6543 & $3.53383 \mathrm{e}^{-040}$ & 15.965430 & 9.12045 & 14.987 \\
\hline
\end{tabular}

Secondly, the performance of proposed system is investigated by varying the input power with SMF-DCF-EDFA techniques. The different Eye-diagrams are evaluated from simulated model with different values of input power as shown in Fig.6. It can be observed that, when input power increases, closing of eye remains distorted while we compare the Eye-diagrams and clearly opening of eye-diagram is obtained at $5 \mathrm{dBm}$ input power. Therefore, we choose the optimized output power of $\mathrm{CW}$ laser at $5 \mathrm{dBm}$. Further, the output readings of optimized parameters with corresponding input power are given in Table. 3 . 

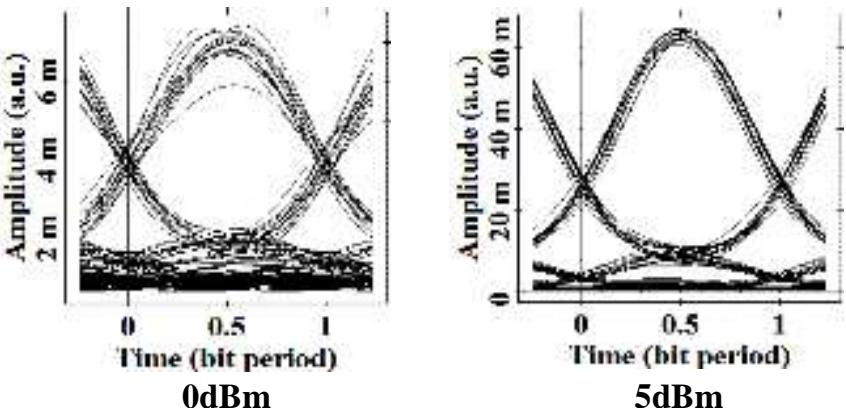

$5 \mathrm{dBm}$

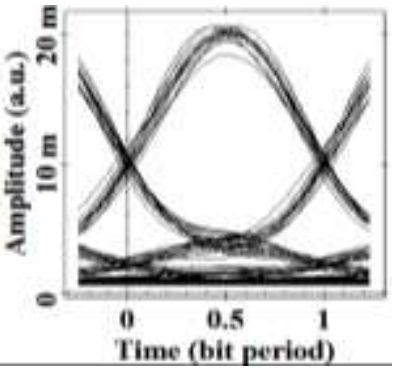

$10 \mathrm{dBm}$

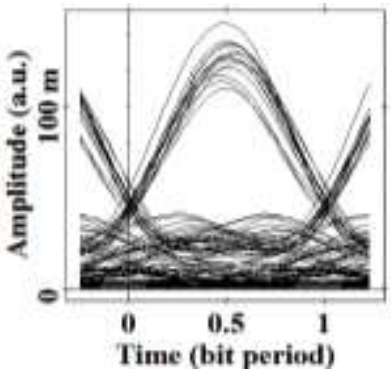

$20 \mathrm{dBm}$

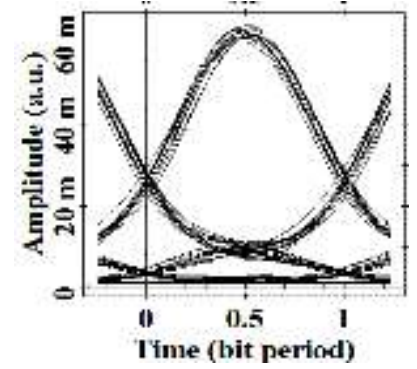

$15 \mathrm{dBm}$

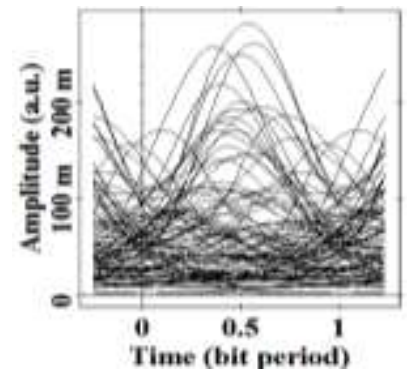

$25 \mathrm{dBm}$

Fig.6. Eye-diagrams of received signals from proposed optical fiber transmission system with different values of input power

Table.3. Performance parameters of simulated model by varying input power

\begin{tabular}{|c|c|c|c|c|c|}
\hline $\begin{array}{c}\text { Input } \\
\text { Power } \\
\text { (dBm) }\end{array}$ & $\begin{array}{c}\text { Max Q- } \\
\text { Factor }\end{array}$ & Min BER & $\begin{array}{c}\text { Gain } \\
(\mathbf{d B})\end{array}$ & $\begin{array}{c}\text { Noise } \\
\text { Figure } \\
(\mathbf{d B})\end{array}$ & $\begin{array}{c}\text { Output } \\
\text { Power } \\
(\mathbf{d B m})\end{array}$ \\
\hline 0 & 160.2819 & $6.16003 \mathrm{e}^{-014}$ & 25.8706 & 6.1839 & 13.817 \\
\hline 5 & 149.895 & $1.93068 \mathrm{e}^{-023}$ & 20.7409 & 6.1526 & 13.987 \\
\hline 10 & 125.741 & $1.63383 \mathrm{e}^{-037}$ & 12.2840 & 6.1269 & 13.450 \\
\hline 15 & 110.885 & $1.03539 \mathrm{e}^{-009}$ & 8.19702 & 6.1481 & 13.438 \\
\hline 20 & 95.1751 & 0.2006002 & 6.20725 & 7.5311 & 14.876 \\
\hline 25 & 89.7461 & 0.1606002 & 5.45020 & 8.6321 & 14.950 \\
\hline
\end{tabular}

Lastly, the performance of proposed system is investigated by varying the attenuation coefficient with SMF-DCF-EDFA techniques. The different Eye-diagrams are evaluated from simulated model with different values of attenuation coefficient as shown in Fig.7. It can be observed that, when attenuation increases, closing of eye remains distorted while we compare the Eye-diagrams and higher eye opening is obtained at attenuation coefficient of $0.2 \mathrm{~dB} / \mathrm{km}$. Therefore, we choose a minimum attenuation coefficient of optical fiber for the proposed optical system to obtain the finest value of performance parameters.

Further, the output readings of optimized parameters with corresponding attenuation coefficient are given in Table.4.

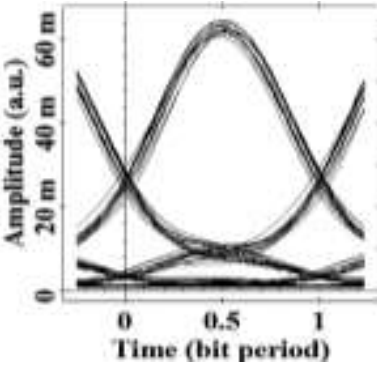

$0.2 \mathrm{~dB} / \mathrm{km}$

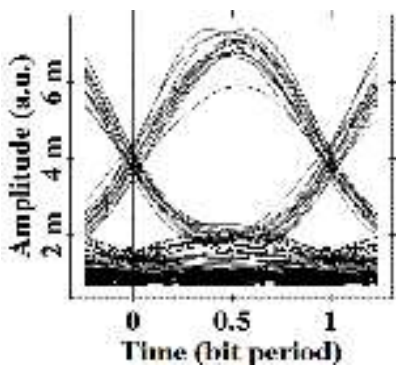

$0.35 \mathrm{~dB} / \mathrm{km}$

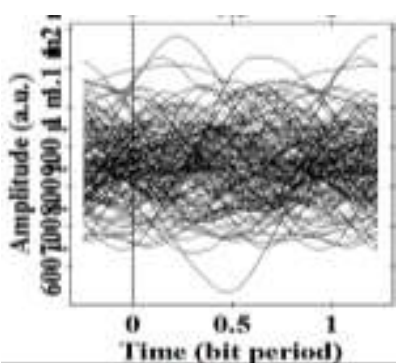

$1 \mathrm{~dB} / \mathbf{k m}$

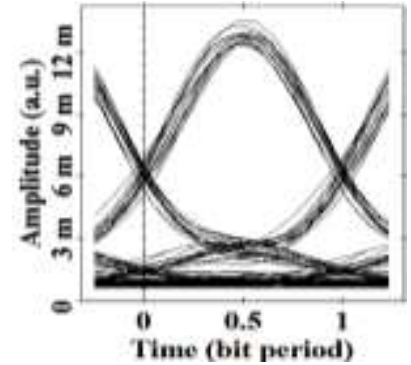

$0.25 \mathrm{~dB} / \mathrm{km}$

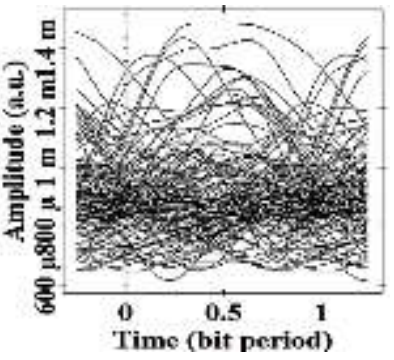

$0.5 \mathrm{~dB} / \mathrm{km}$

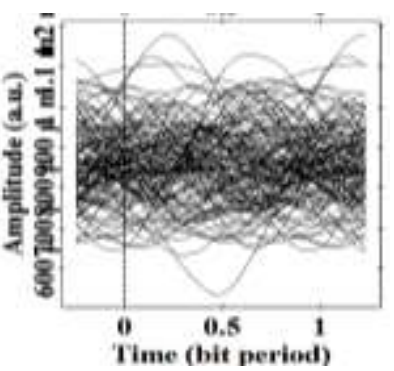

$3 \mathrm{~dB} / \mathrm{km}$
Fig.7. Eye-diagrams of received signals from proposed optical fiber transmission system with different values of attenuation coefficient

Table.4. Performance parameters of simulated model by varying attenuation coefficient

\begin{tabular}{|c|c|c|c|c|c|}
\hline $\begin{array}{c}\text { Attenuation } \\
(\mathbf{d B} / \mathbf{K m})\end{array}$ & $\begin{array}{c}\text { Max Q- } \\
\text { Factor }\end{array}$ & Min BER & $\begin{array}{c}\text { Gain } \\
(\mathbf{d B})\end{array}$ & $\begin{array}{c}\text { Noise } \\
\text { Figure } \\
\mathbf{( d B})\end{array}$ & $\begin{array}{c}\text { Output } \\
\text { Power } \\
(\mathbf{d B m})\end{array}$ \\
\hline 0.2 & 145.7412 & $1.63383 \mathrm{e}^{-037}$ & 18.2840 & 6.1269 & 15.011 \\
\hline 0.25 & 135.8914 & $2.46648 \mathrm{e}^{-028}$ & 15.6949 & 17.6911 & 15.990 \\
\hline 0.35 & 70.2253 & $3.46648 \mathrm{e}^{-020}$ & 10.5693 & 36.6955 & 15.890 \\
\hline 0.5 & 0.00243 & $5.46648 \mathrm{e}^{-020}$ & -14.0321 & 30.3560 & 9.346 \\
\hline 1 & 0 & 1 & -12.0654 & 48.1966 & 7.734 \\
\hline 3 & 0 & 1 & -8.1695 & 56.2974 & -5.734 \\
\hline
\end{tabular}

It can be concluded from the above discussions; the quality of eye opening of received signal is much clear by applied SMFDCF-EDFA compensation techniques with optimized parameters and provides the best possible performance for dispersion compensation. Furthermore, the Table.5 summarized the comparative analysis of the proposed work along with similar research work reported earlier [12]-[16]. 
Table.5. Comparative analysis of proposed work with similar research work reported previously using deliberated DCF-EDFA techniques

\begin{tabular}{|c|c|c|c|c|c|c|c|}
\hline \multirow{2}{*}{\begin{tabular}{|c|} 
Technique \\
or \\
Parameters \\
\end{tabular}} & $\begin{array}{c}\text { Proposed } \\
\text { Work }\end{array}$ & [12] & [13] & [14] & \multicolumn{2}{|c|}{ [15] } & [16] \\
\hline & DCF & FBG & FBG & CFBG & FBG & DCF & DCF \\
\hline \begin{tabular}{|l} 
Max Q- \\
Factor
\end{tabular} & 145.5749 & 50.2712 & 40.209 & 81.4650 & - & - & 33.7767 \\
\hline Min BER & $\begin{array}{c}1.47701 \mathrm{e}^{-} \\
119\end{array}$ & $\begin{array}{c}4.02312 \\
\mathrm{e}^{-014}\end{array}$ & - & $\begin{array}{c}3.08032 \\
\mathrm{e}^{-017}\end{array}$ & - & - & $\begin{array}{c}1.80195 \\
\mathrm{e}^{-027}\end{array}$ \\
\hline Gain $(\mathrm{dB})$ & 18.4998 & 14.4298 & 10.920 & 25.4509 & 8.23 & 1.45 & - \\
\hline $\begin{array}{l}\text { Output } \\
\text { Power } \\
(\mathrm{dBm})\end{array}$ & 16.223 & 12.205 & 12.094 & 16.807 & 7.40 & 2.94 & 2.453 \\
\hline $\begin{array}{l}\text { Noise Figure } \\
(\mathrm{dB})\end{array}$ & 6.40983 & 8.0812 & 24.342 & 5.275 & - & - & 37.320 \\
\hline $\begin{array}{l}\text { DCF Length } \\
(\mathrm{km})\end{array}$ & 18 & - & - & - & - & 22 & 30 \\
\hline \begin{tabular}{|l|} 
CFBG \\
Length $(\mathrm{mm})$
\end{tabular} & - & 75 & 85 & 90 & 50 & - & - \\
\hline
\end{tabular}

\section{CONCLUSIONS}

The presented work is highlighted on performance analysis of optical transmission system over a fiber length of $18 \mathrm{~km}(15 \mathrm{~km}-$ $\mathrm{SMF}+3 \mathrm{~km}-\mathrm{DCF}$ ) for $10 \mathrm{Gbps}$ data speed. The proposed model is designed and simulated using dispersion compensation (DCFEDFA) schemes having EDFA amplifier in order to compensate the dispersion and attenuation effects. The performance of designed optical system is investigated in terms of parameters Qfactor, BER gain, output power, noise figure and Eye-diagrams for NRZ modulation format by varying the fiber length $(\mathrm{km})$, input power $(\mathrm{dBm})$ and attenuation constant $(\mathrm{dB} / \mathrm{km})$. In future, the proposed techniques can be applied to a complex optical system with large number of channels to compensate the dispersion and attenuation complications.

\section{REFERENCES}

[1] B. Mukherjee, "WDM Optical Communication Networks: Progress and Challenges", IEEE Journal on Selected Areas in Communications, Vol. 18, No. 10, pp. 1810-1824, 2000.

[2] B. Chomycz, "Planning Fiber Optic Networks", McGrawHill, 2000.

[3] K.R. Ramaswami, H. Sivarajan and H.G. Sasaki, "Optical Networks", Elsevier, 2000.

[4] P. Anuseetal and S. Singh, "Analysis of EDFA based 16Channel C-Band Optical WDM System for Different Pumping Schemes", International Journal of Advanced Research in Electrical, Electronics and Instrumentation Engineering, Vol. 5, No. 6, pp. 12-18, 2016.

[5] S. Semmalar and S. Malarkkan, "Optical Signal Power Analysis in Erbium-Doped Fiber Amplifier with Pump
Power and Length Variation using Various Pumping Techniques", ISRN Electronics, Vol. 16, No. 2, pp. 1-8, 2013.

[6] B.H. Choi, H.H. Park and M.J. Chu, "New Pump Wavelength of 1540-nm Band for Long-Wavelength-Band Erbium-Doped Fiber Amplifier (L-Band EDFA)", IEEE Journal of Quantum Electronics, Vol. 39, No. 10, pp. 12721280, 2003.

[7] R.S. Kaler, Ajay K Sharma and T.S. Kamal, "Comparison of Pre, Post and Symmetrical Dispersion Compensation Schemes for $10 \mathrm{~Gb} / \mathrm{s}$ NRZ Links using Standard and Dispersion Compensated Fibers", Elsevier Optics Communication, Vol. 209, No. 1-3, pp. 107-123, 2002.

[8] P. Singh and R. Chahar, "Performance Analysis of Dispersion Compensation in Long Haul Optical Fiber using DCF", International Journal of Engineering and Science, Vol. 2, No. 7, pp. 18-22, 2014.

[9] Govind P. Agrawal, "Fiber Optics Communication Systems", $3^{\text {rd }}$ Edition, John Wiley and Sons, 2002.

[10] Neheeda P, Pradeep M and Shaija P.J, "Analysis of WDM System with Dispersion Compensation Schemes", International Conference on Advances in Computing and Communications, Vol. 93, No. 1, pp. 647-654, 2017.

[11] M. Othman, "An Analysis of 10Gbits/s Optical Transmission System using fiber Bragg Grating (FBG)", IOSR Journal of Engineering, Vol. 2, No. 7, pp. 55-61, 2012.

[12] K. Kumar, "Performance Analysis of Dispersion Compensation using Fiber Bragg Grating (FBG) in Optical Communication", International Journal of Current Engineering and Technology, Vol. 4, No. 3, pp. 1527-1531, 2014.

[13] B. Prasad, K.C. Patra and N.K Barpanda, "Performance Analysis of Fiber Optical Communication using Fiber Bragg Grating as Dispersion Compensator", International Journal of Advanced Research in Electrical, Electronics and Instrumentation Engineering, Vol. 5, No. 4, pp. 2729-2733, 2016.

[14] Mounia Chakkour, Otman Aghzout, Badiaa Ait Ahmed, Fahd Chaoui, and Mounir El Yakhloufi, "Chromatic Dispersion Compensation Effect Performance Enhancements using FBG and EDFA-Wavelength Division Multiplexing Optical Transmission System", Internal Journal of Optics, Vol. 2017, pp. 1-8, 2017.

[15] N. Mohammed, M. Solaiman and M. Aly, "Design and Performance Evaluation of a Dispersion Compensation Unit using Several Chirping Functions in a TANH Apodized FBG and Comparison with Dispersion Compensation Fiber”, Applied Optics, Vol. 53, No. 29, pp. 239-247, 2014.

[16] M.L. Meena and Deepika Meena, "Performance Analysis of DWDM Optical Network with Dispersion Compensation Techniques for $4 \times 8 \mathrm{Gbps}$ Transmission System", ICTACT Journal on Microelectronics, Vol. 4, No. 2, pp. 613-617, 2018. 